\title{
Kognitiivne usundilugu
}

\author{
$\underline{\text { Ilkka Pyysiäinen }}$
}

1990. aastail tõusis usundiloos esile uuelaadne lähenemisviis, mida on nimetatud «kognitivismiks» või «kognitiivseks usundipsühholoogiaks (vt Malley 1996). Selle keskne mõte on, et religioossete uskumuste ja neil põhineva käitumise iseloomu saab seletada inimmeele/mõistuse universaalselt samasuguste joonte abil. Seda lähenemisviisi kutsutakse «kognitiivseks», kuna selles kasutatakse psühholoogia, tehisintellekti uurimise, keeleteaduse, samuti neuroteaduste alal tehtud tunnetuse uurimusi. Tunnetuse all omakorda mõistetakse mõtlemist, mälu, tähelepanu, teadvust ja muid mentaalseid protsesse. Nende uurimine on viimastel aastatel tormiliselt edenenud, kuid ulatunud oma mõjuga usundiuurimisse aeglasemalt.

\section{Tunnetus ja usundiuurimine}

Usundiloo seisukohast tähendab see, et tähelepanu suunatakse sellele, kuidas inimmõistuse tegevust juhtivad põhimõtted mõjutavad usundinähtuste omandamist ja levimist. Seega ei piisa, et uuritakse vaid usundilisi ainestikke ja üritatakse nende põhjal järeldada, kuidas toimib mõistus, mis on need loonud. Nii toimides suubutakse ringotsustustesse ja kattetuisse spekulatsioonidesse, nagu on sagedane näiteks Lévi-Straussi strukturalismis. Uurijal peab olema oma spetsiifilistest ainestikest sõltumatut evidentsi sellest, kuidas mõistus toimib, ja alles selle valguses võidakse luua hüpoteese, mida testitakse usundiliste ainestike abil (vt Boyer 1993a).

Uurimises on võimalik eristada generatiivseid ja selektiivseid malle. Generatiivsed mallid seletavad, kuidas erisugused religioossed uskumused sünnivad, nagu üritavad teha vanad niinimetatud «usundi algupärateooriad» (vt Honko \& Pentikäinen 1975: 52-53). Selektiivsed mallid seletavad, miks teatud uskumused ja muud usundilised mentaalsed representatsioonid on laialt levinud. Nagu ütleb Pascal Boyer (1994b: ix), piisab erilaadsete uskumuste olemasoluks sellest, et teistel inimestel on neid varem olnud. Religioossed uskumused on seega olemas, sest nad on võimalikud ja seetõttu tulevad nad varem või hiljem kellelegi pähe (Pyysiäinen, b - trükkimisel). Uurijal jääb vaid seletada, miks need ei jää ainult ühe inimese meeleliikumiseks/mõttekäiguks, vaid saavad kultuuri osaks ja hakkavad mõjutama laiade inimhulkade elu (Boyer 1994b).

Hea näide selektiivsetest mallidest on prantsuse antropoloogi Dan Sperberi $(1995 ; 1996)$ «uskumuste epidemioloogia».

Sperberi järgi võib uskumuste struktuurist leida jooni, mis muudavad need hõlpsasti meeldesööbivaiks. Kergesti meeldejäävaid uskumusi jutustatakse tõenäolisemalt edasi, mis omalt poolt seletab nende laia levikut. Kummatigi ei levi uskumused muutumatuina, vaid muunduvad vahendusprotsessi käigus (Sperber \& Wilson 1988).

Kõigile sümboolsetele uskumustele omaselt kuuluvad nad mõisteliste, mitte empiiriliste teadmiste hulka. Sellistena on nad ka mitmete tõlgendusvõimalustega ja selles mõttes ebatäielikult mõistetud, et neid võib lõpmatult uuesti tõlgendada. Me justkui paneme jutumärkidesse sellised usundilised representatsioonid nagu kasvõi 'Jeesus on Jumala poeg', ja saame nõnda näiteks representatsiooni «'Jeesus on Jumala poeg' on õige». Inimesel ei tarvitse olla mingit ühetähenduslikku arusaama sellest, mida täpselt võttes tähendab 'Jeesus on Jumala poeg', suutmaks seda meeles pidada ja uskumaks, et tegemist on tähtsa asjaga. Niisugust religioosset teadmist protsesseeritakse sümboolselt nii, et inimmõistus esitab justkui pärin- 
guid mälule, leidmaks selliseid representatsioone, mis sobivad kokku uskumusega, millest lähtuti. See ei vii ometi mingi lõpliku tõlgenduseni, sest tõlgendusprotsess on lõpmatu (Sperber 1995; 1996.)

\section{Boyeri mall}

Boyer (1994b) on arendanud vastavatüübilist lähenemisviisi nimelt usundiloos kasutamiseks. Ta lähtub asjaolust, et kuigi mingi üksikuskumus ei ole vältimatult täiesti universaalne, kõigis kultuurides leiduv, pole religioossete ideede spekter ometi ääretu. Teatud struktuurid või vormid (patterns) korduvad ja teisi ei esine hoopiski. Korduvad vormid peavad põhinema teatud üldinimlikel kognitiivsetel struktuuridel. See tähendab, et uskumusi ei saa seletada pelgalt viitamisega nende «kultuurikontekstile», nagu kultuurantropoloogias on sageli kombeks olnud. Uskumused peegeldavad lisaks oma kultuurilisele kontekstile ka inimtunnetuse loomust. Neis on seega nii varieerumist kui samasugusust (vt Boyer 1998).

Teiselt poolt ei tohi unustada, et meie kognitiivsed võimed on arenenud evolutsiooni käigus ja vastastikustes mõjutustes ümbritseva tegelikkusega. Me ei saa õigupoolest tõmmata täpset piiri välismaailma ja inimmõistuse/aju vahele. Aju aitab meil visandada maailma kontuure, kuid on teiselt poolt ise selle maailma osa ja bioloogilise arengu tulemus. See ehk võõrastavalt kõlav väide saab mõistetavaks, kui kaalume mõtlemise ja mäletamise loomust praktikas. Inimmõistus ei ole välismaailmast eraldatud saareke, vaid vahendaja iseenda ja muu maailma vahel. Meie mõtlemisvõime on mitmel viisil välismaailmast sõltuv, me võime näiteks kirjutada asju paberile, pidamaks neid paremini meeles, tuttav paik toob meelde teatud mälestusi ja nii edasi. Mõtlemise objektid ei eksisteeri seega ainult mõistuses, vaid ka maailmas (vrd Sartre 1995), ja küsimus on inimmõistuse ja välismaailma vahelistes vastastikustes mõjutustes (Clark 1997; Elman et al. 1998). Nõnda seletub religioossete uskumuste teatud samasugusus lõppude lõpuks sellega, et inimaju/mõistus on kõikjal väga ühesugune, mis omakorda johtub sellest, et välismaailma loodud raamid on osalt kõikjal samasugused. Teadagi erinevad looduskeskkonnad ja ökoloogilised olud maailma eri paigus üksteisest, kuid sellegipärast on need ka mitmel viisil samasugused, mistõttu ka inimene on maailma eri paigus arenenud suuresti samasuguseks. Näiteks ei saa materiaalsed kehad üheski kultuuris olla üheaegselt kahes eri paigas, inimesed ei saa minna läbi seinte, raskusjõud mõjub kividele ja muudele rasketele kehadele jms. Selliseid seiku on lugematul hulgal ja on selge, et inimesed mõistavad neid asju kõikjal ühtmoodi ja oskavad neid oma käitumises arvesse võtta.

Paljud antropoloogid on kummatigi soovinud seda vaidlustada, kuna nende järgi on ühes või teises hõimus peetud täiesti loomulikuks, et kivid kõnelevad, puudel on tunded, inimesed võivad lennata vms.

Nõnda väitvad antropoloogid pole märganud, et sellised uskumused on alati teatud erandjuhtumid. Ükski hõim ei usu, et kõik kivid kõnelevad, et kõik inimesed oskavad lennata jne. Täpsemini öeldult: kuigi inimestel on teatud erilisi uskumusi, millest nad on teadlikud, käituvad nad ometi oma igapäevases elus nii, et erilisi uskumusi võetakse arvesse vaid erandjuhtumeil. Teisiti öeldes: kuigi näiteks mõningaid kivisid peetakski personaalseteks olenditeks, siis normaalselt käies tallavad inimesed ometi muretult jalgadega kive või loobivad neid nagu mistahes elutuid asju. Ainult teatud eriolukordades mõeldakse teatud kividest, et nad on tundvad olendid (Boyer 1994b; Atran 1996: 241-242).

Boyer (1994a, b; 1996; 1999; 2000) on võtnud kasutusele terminid 'intuitiivne' ja 'intuitsioonivastane' tähistamaks erisuguseid teadmise vorme. 'Intuitiivne ontoloogia' tähendab tegelikkuse olemust puudutavaid mõisteid, mis on nii iseenesestmõistetavad, et neist ei olda tead- 
likud, ja mis on kõigis kultuurides samasugused. Sellesse intuitiivsesse teadmisse kuulub muuhulgas materiaalsete esemete, elusolendite ja inimisiksuste eristamine üksteisest nii, et nende käitumist seletatakse erinevatelt alustelt. Küsimus ei ole eksplitsiitsetes uskumustes, vaid nimelt teadvustamata teadmises, mis juhib käitumist. Kuigi inimesel oleks mistahes eksplitsiitseid uskumusi neist kolmest objektiklassist, kohtlevad nad praktikas ometi nende klasside olendeid eri viisil. Kive ja kände näiteks üldiselt ei oodata kuulvat, mida neile räägitakse, ega inimesi ja loomi elavat tuhandeid aastaid. Niisugune intuitiivne teadmine on suurelt osalt kas kaasasündinud või siis õpitakse see väga vara, võib-olla sünnipäraste eelduste põhjal. Näiteks oskavad juba imikuealised oodata, et hooga teise vastu põrkav piljardipall tõukab teise palli samas suunas liikuma (mitte näiteks vastupidi). Niisuguseks teadmiseks näib inimlapsel olevat kaasasündinud valmidus, kuna teisiti ei saaks seletada, kuidas lapsed õpivad kõike seda nii kiiresti ja vaevatult (vt Karmiloff-Smith 1992; Elman et al. 1998; Lawson 1999; Lawson - trükkimisel).

Aga inimesed on võimelised moodustama ka intuitsioonivastaseid uskumusi. Miski ei takista meid näiteks kujutlemast, et mõned kivid kuulevad meie juttu, et mõni inimene on võinud surnuist üles tõusta, et on olemas kehatuid vaime jne. Sellised uskumused on meie intuitiivsete ootuste vastu, kuid me saame neid siiski tõeks pidada. Sel juhul mõtleme, et meie intuitsioon on ositi puudulik. See annab küll üldiselt õige pildi asjadest, kuid tegelikkuses mõeldakse olevat ka meile tundmatuid, intuitsioonivastaseid ulatuvusi. Intuitsioonivastased uskumused on tähelepanu köitvad ja üldiselt suure huvi objektid. Boyer on paljude empiiriliste testidega osutanud, et inimesed mäletavad parajal määral intuitsioonivastaseid uskumusi paremini kui muid, mistõttu need ka levivad hõlpsasti. See seletab Boyeri arvates, miks üle maailma võib kohata samalaadseid erilisi uskumusi - nad on levinud tänu heale mäletatavusele ja huvitavusele. Sellistes uskumustes on mingi teatud intuitsioonivastane joon, kuid samal ajal sisaldavad nad ka palju intuitsioonipärast. Liiga intuitsioonivastast uskumust oleks raske meeles pidada ja sellest oleks raske teha praktilisi järeldusi. Näiteks kuju, mis kuuleb selle kõrval palvetava inimese juttu, on sobivalt intuitsioonivastane, kuid kuju, mis kuuleb palveid saja kilomeetri tagant, on liiga intuitsioonivastane - selliseid uskumusi suulises pärimuses peaaegu ei esine. Kõiketeadev Jumal taas võib kuulda palveid ükskõik millal, aga see põhineb Jumala kõikjal ligiolekul. Intuitsioonivastane on seega ainult asjaolu, et Jumalal pole normaalset keha (kuigi tema psühholoogia on ootuspärane). Kuju, mis kuuleb palveid saja kilomeetri tagant, oleks seevastu intuitsioonivastane kahes eri mõttes: füüsilisel kehal on erandlik võime ja see võime on erandlik ka iseenesest (kaugelt kuulmine) (Boyer 1994b; 1998; Boyer - trükkimisel).

Boyeri järgi moodustavad intuitsioonivastased ideed usundiliste ideede klassi, kuigi intuitsioonivastasus üksinda pole piisav usundi kriteerium (Boyer 1994a: 408; 1994b: 122, 124), sest on ju ka näiteks mõnedki teaduslikud mõisted ja teooriad intuitsioonivastased. Boyer'i teooria nõrk koht on seik, et uskumuse religioossus pole kunagi uskumuse sisemine omadus, vaid sõltub sellest, millise tähenduse inimesed sellele annavad. Tähenduse andmine on omakorda seoses tundekogemustega. Usundi tundemärgiks võidakse pidada intuitsioonivastaseid representatsioone, mida usutakse olevat tõsi, mis on ühiskondlikult jagatud, millesse suhtutakse tõsiselt ning tundepäraselt ja mille abil liigendatakse oma elu (Pyysiäinen a ja b trükkimisel). Nõnda siis põhineb usund sellel, et inimestel liigina on arenenud võime moodustada mentaalseid representatsioone, mis ei vasta meie intuitiivsele kogemusele maailmast (Mithen 1998). Selliseid representatsioone on ka teaduses, kunstis ja meelehäiretega inimeste uskumustes. Nendest muudest erineb usund sellega, et usundis peetakse intuitsioonivastaseid representatsioone tõeks ja inimese elu seisukohalt äärmiselt tähendusrikkaiks. Lisaks näib usundis olevat keskne usk intuitsioonivastastesse agentidesse ehk toimijaisse. Intuitiivsete 
ontoloogiate raames on agent olend, kes liigub, nagu oleks tal oma sisemine energiaallikas, kes käitub sihipäraselt ja kellel on kognitiivseid võimeid (Leslie 1994; 1996). Juba väga väikesed lapsed oskavad eristada agente muudest olenditest. Kui lapsele näiteks öeldakse, et hyrax (mis on pelgalt väljamõeldud sõna) on väsinud, siis oskab laps kohe järeldada, et hyrax võib olla ka näljane ja osata nutta, kuid ei saa olla metallist tehtud. Hyrax on selgesti agent, ja laps mõistab, et selle iseloomu ja tegevust tuleb seletada erinevatel põhimõtetel kui näiteks metallist tehtud esemete puhul (vt Boyer 1993b). See kajastab kognitiivsete võimete piirkonnaspetsiifilisust ehk seda, et inimesed mõtlevad eri viisil sellistest erinevatest asjadest nagu esemed, organismid ja isikud. Pole olemas mõtlemist üleüldse, vaid igasugune mõtlemine on ikka mingi asja mõtlemine, ja mõeldav asi/objekt mõjutab ise mõtlemise iseloomu. Inimmõistus ei ole probleeme lahti harutav üldmasin, vaid kogum «mooduleid» ehk eripiirkondi (Hirschfeld \& Gelman 1994). Kui religioonis on agentidel keskne osa, siis põhineb see loomulikul, evolutsiooni käigus arenenud võimel ära tunda ja eristada agente muusugustest olenditest. Usundi piires esinevad just nimelt intuitsioonivastased agendid, nagu jumalad, vaimud jne. Need järgivad tavalist argipsühholoogiat, kuid neil on põikuvaid bioloogilisi ja füüsilisi omadusi. Esialgse empiirilise ainestiku valguses tundub, et inimesed peavad nimelt intuitsioonivastaseid agente parimaks religiooni tunnuseks (Lawson \& McCauley 1990; Lawson 1999; 2000; Lawson - trükkimisel; Pyysiäinen a, b - trükkimisel; Pyysiäinen \& Lindeman \& Honkela - trükkimisel). Selle põhjal on võimalik liigitada religioossete uskumuste kirju spekter õige kokkusurutud tüpoloogiaks, mis koosneb viiest ontoloogilisest kategooriast (isiksus, loom, taim, ese, elutu looduselement) ja kolmest teadmispiirkonnast (psühholoogia, bioloogia ja füüsika). Kõik spetsiaalsed intuitsioonivastased usundilised representatsioonid on moodustatud neid faktoreid intuitsioonivastaselt ühendades (Boyer 2000).

\section{Lõpetuseks}

Niisiis võime kognitiivsest vaatenurgast seletada religioossete uskumuste moodustumist, vastuvõtmist ja levimist selle teadusliku informatsiooni valgusel, mis meil on inimmõistuse toimimise kohta. Sel juhul ei võta me seisukohta religioossete uskumuste tõele vastavuse suhtes, vaid vaatleme üksnes nende kognitiivseid omadusi. Me ei hinda seda, kui tõepärast või õiget pilti maailmast nad vahendavad, vaid vaatleme, kuidas uskumused kujunevad ja levivad. Küsimuse all on seega selle seletamine, kuidas religioon toimib.

Üks tähelepandav järeldus sellest on, et mõiste religioon satub uude valgusse, kui mõistetakse, et religioossed uskumused on täiesti nendesamade kognitiivsete mehhanismide tooted nagu muudki inimlikud uskumused. Niisiis pole olemas mingeid spetsiifilisi religioosseid kognitiivseid mehhanisme, samuti pole religioon mingi iseseisev tunnetuspiirkond. 'Religiooni' nimesildi alla on riputatud terve hulk kõige erinevamaid nähtusi, millega ühenduses aktiviseeruvad näiteks eetilised, sotsiaalsed, esteetilised jm representatsioonid. Religioon on omalaadne «parasiit» selle kõige muu küljes. Mingi konkreetne intuitsioonivastane representatsioon võib olla samahästi kunstiline, fiktiivne, skisofreeniline või religioosne. Milline neist ta on, sõltub sellest, missuguses seoses ta esineb, kelle meeles see representeerub ja millisel viisil seda kasutatakse. Teiselt poolt võib religioosses kasutuses olev representatsioon olla samaaegselt religioosne ja näiteks kunstiline. Kui me ütleme, et religioossete nähtuste seletamiseks ei tarvitse oletada mingeid erilaadseid religioosseid mehhanisme, siis jõuame teadagi Jumala ilmutuse ja valgustuse välistamiseni religioossete uskumuste olemasolu põhjuste hulgast. See pole siiski sama kui väita, et näiteks ilmutatud teadmine on võimatu. Väidame vaid, et inimeste religioosset mõtlemist ja käitumist võib teaduse piires päris 
hästi seletada ilma nende oletusteta. Teiselt poolt, kui ka mõned religioossed uskumused oleksidki saadud Jumala ilmutusena või valgustuskogemuse tagajärjel, siis me ei suudaks neid kunagi eristada muudest, inimlikest uskumustest (Pyysiäinen 1999: 118), kuna «ilmutatud» ja «loomuliku» teadmise eristamiseks peaks suutma näha otse «üleloomulikku» tegelikkusse. Ja kuna just see võime põhineb üksnes ilmutusel, siis peaks olemas olema ilmutust puudutav ilmutus. Ja siis ka ilmutust puudutav ilmutust puudutavat ilmutus ja nii edasi ad infinitum. Kuigi teatud religioossed uskumused oleksidki saadud mingil «üleloomulikul» viisil, levivad nad ometi kultuuris inimliku mõtlemise ja käitumise seaduspärasuste kohaselt. Ja neid seaduspärasusi uurib usundilugu.

Tõlkinud Kristi Salve

\section{Kirjandus}

Atran, Scott 1996. Modes of thinking about living kinds. Modes of Thought (toim. D. R. Olson \& N. Torrance). New York, lk 216-260.

Boyer, Pascal 1993a. Cognitive aspects of religious symbolism. Cognitive Aspects of Religious Symbolism (toim. P. Boyer). Cambridge, 1k 4-47.

Boyer, Pascal 1993b. Pseudo-natural kinds. Cognitive Aspects of Religious Symbolism (toim. P. Boyer). Cambridge, lk 121-141.

Boyer, Pascal 1994a. Cognitive constraints on cultural representations: Natural ontologies and religious ideas. Mapping the Mind (toim. L. Hirschfeld \& S. Gelman). Cambridge, lk 39-67. Boyer, Pascal 1994b. The Naturalness of Religious Ideas. A Cognitive Theory of Religion. Berkeley \& Los Angeles \& London.

Boyer, Pascal 1996 (1995). Causal understandings in cultural representations: Cognitive constraints on inferences from cultural input. Causal Cognition (toim. D. Sperber, D. Premack, and A. J. Premack). Oxford, lk 615-644.

Boyer Pascal 1998. Cognitive tracks of cultural inheritance: How evolved intuitive ontology governs cultural transmission. American Anthropologist, 100, 1k 876-889.

Boyer, Pascal. 1999. Cognitive aspects of religious ontologies: How brain processes constrain religious concepts. Approaching Religion, I (toim. T. Ahlbäck), lk 53-72. (Scripta Instituti Donneriani, 17: 1) Åbo.

Boyer, Pascal. 2000. Evolution of a modern mind and the origins of culture: religious concepts as a limiting case. Evolution and the Human Mind: Modularity, Language and Meta-Cognition (toim. P. Carruthers \& A. Chamberlain). Cambridge.

Boyer, Pascal. Cognitive inheritance tracks for cultural representations. The Debated Mind: evolutionary psychology versus ethnography. Oxford: Berg. Trükkimisel.

Clark, Andy 1997. Being There. Putting Brain, Body, and World Together Again. Cambridge. Elman, Jeffrey L. et al. 1998 (1996). Rethinking Innateness. A Connectionist Perspective on Development. Cambridge, MA \& London.

Hirschfeld, Lawrence A. \& Susan A. Gelman 1994. Toward a topography of mind: An introduction to domain specificity. Mapping the Mind (toim. L. Hirschfeld \& S. Gelman). Cambridge, lk 3-35. Honko, Lauri \& Juha Pentikäinen 1975 (1970). Kulttuuriantropologia. Helsinki. Karmiloff-Smith, Annette 1992. Beyond Modularity. A Developmental Perspective on Cognitive 
Science. Cambridge, MA \& London.

Lawson, E. Thomas. 1999. Keeping Religion in Mind. Approaching Religion, I (toim. T. Ahlbäck), lk 139-149. (Scripta Instituti Donneriani, 17: 1). Åbo.

Lawson, E. Thomas 2000. Psychological perspectives on agency. Religion in Mind: Cognitive

Perspectives on Religious Experience, Belief, and Behavior (toim. J. Andresen). Cambridge.

Trükkimisel.

Lawson\&McCauley 1990. Rethinking Religion. Cambridge.

Leslie, Alan 1994. ToMM, ToBy, and Agency: Core architecture and domain specificity. Mapping the Mind (toim. L. Hirschfeld \& S. Gelman). Cambridge, lk 119-148.

Leslie, Alan 1996 (1995). A theory of agency. Causal Cognition (toim. D. Sperber, D. Premack \& A. J. Premack). Oxford, lk 121-141.

Malley, Brian E. 1996. The emerging cognitive psychology of religion: A review article. Method \& Theory in the Study of Religion 8, 1k 109-141.

Mithen, Steven 1998 (1996). The Prehistory of the Mind. London.

Pyysiäinen, Ilkka 1999. God as ultimate reality in religion and in science. Ultimate Reality and Meaning 22, lk 106-123.

Pyysiäinen, Ilkka a. 2000. Cognition, emotion, and religious experience. Religion in Mind:

Cognitive Perspectives on Religious Experience, Belief, and Behavior (toim. J. Andresen).

Cambridge. Trükkimisel.

Pyysiäinen, Ilkka. b. How Religion works. (Toronto Studies in Religion.) Toronto. Trükkimisele antud.

Pyysiäinen, Ilkka \& Lindeman, Marjaana \& Honkela, Timo. Religion and counter-intuitive representations. The International Journal for the Psychology of Religion. Trükkimisel.

Sartre, Jean-Paul 1995 (1936-1937). The Transcendence of the Ego. An Existentialist Theory of Consciousness. Tõlkinud F. Williams and R. Kirkpatrick. New York.

Sperber, Dan 1995 (1974). Rethinking Symbolism. Cambridge.

Sperber, Dan 1996. Explaining Culture. A Naturalistic Approach. Oxford.

Sperber, Dan \& Deirdre Wilson 1988 (1986). Relevance. Communication and Cognition.

Cambridge. 